\title{
The impact of anthropogenic chlorine emissions, stratospheric ozone change and chemical feedbacks on stratospheric water
}

\author{
T. Röckmann ${ }^{1}$, J.-U. Grooß ${ }^{2}$, and R. Müller ${ }^{2}$ \\ ${ }^{1}$ Max-Planck-Institut für Kernphysik, Bereich Atmosphärenphysik, 69117 Heidelberg, Germany \\ ${ }^{2}$ Institut für Chemie und Dynamik der Geosphäre, Forschungszentrum Jülich, 52425 Jülich, Germany \\ Received: 17 December 2003 - Published in Atmos. Chem. Phys. Discuss.: 5 February 2004 \\ Revised: 23 April 2004 - Accepted: 28 April 2004 - Published: 7 May 2004
}

\begin{abstract}
Mixing ratios of water $\left(\mathrm{H}_{2} \mathrm{O}\right)$ in the stratosphere appear to increase due to increased input of $\mathrm{H}_{2} \mathrm{O}$ and methane from the troposphere and due to intensified oxidation of $\mathrm{CH}_{4}$ in the stratosphere, but many of the underlying mechanisms are not yet understood. Here we identify and quantify three chemical mechanisms which must have led to more efficient oxidation of $\mathrm{CH}_{4}$ in the stratosphere over the past several decades: 1) The increase in stratospheric chlorine levels due to anthropogenic CFC emissions, 2) the thinning of the stratospheric ozone column and 3) enhanced $\mathrm{OH}$ levels in the stratosphere due to increasing $\mathrm{H}_{2} \mathrm{O}$ levels themselves. In combination with the increase in tropospheric $\mathrm{CH}_{4}$ mixing ratios and with solar cycle related variations of upper stratospheric ozone, these effects can explain about $50 \%$ of the additional conversion of $\mathrm{CH}_{4}$ to $\mathrm{H}_{2} \mathrm{O}$ as observed throughout the stratosphere. The relative contributions from the individual processes have varied over the past decades.
\end{abstract}

\section{Introduction}

The observed increase of water vapour mixing ratios in the stratosphere (Oltmans and Hofmann, 1995; Oltmans et al., 2000; SPARC, 2000; Rosenlof et al., 2001) has received considerable attention because of its importance for the earth's radiative balance (Forster and Shine, 2002). Furthermore, an increase in stratospheric water vapour will have direct impact on stratospheric ozone chemistry (Kirk-Davidoff et al., 1999; Dvortsov and Solomon, 2001). Understanding this increase represents one of the great challenges in present atmospheric research. The collective evidence from numerous in situ and remote sensing measurement series of stratospheric water vapour suggests a positive trend of roughly $0.45 \% / \mathrm{yr}$ (Rosenlof et al., 2001), which may have persisted for about

Correspondence to: T. Röckmann

(t.roeckmann@mpi-hd.mpg.de)
45 years, if the earliest measurements are reliable. Additional insight can be gained from measurements of $\mathrm{CH}_{4}$, because $\mathrm{CH}_{4}$ oxidation is the only substantial in situ source of water in the stratosphere. This means that once an air parcel has entered the stratosphere, its $\mathrm{H}_{2} \mathrm{O}$ mixing ratio gradually increases as $\mathrm{CH}_{4}$ is oxidized. Since two water molecules are formed for each $\mathrm{CH}_{4}$ molecule destroyed, the quantity $\mathrm{H}_{2} \mathrm{O}+2 \times \mathrm{CH}_{4}$ is conserved in the stratosphere, if the mixing ratio of the third hydrogen reservoir, $\mathrm{H}_{2}$, does not change (Jones et al., 1986).

Global remote sensing observations of $\mathrm{H}_{2} \mathrm{O}$ and $\mathrm{CH}_{4}$ from the Halogen Occultation Experiment (HALOE) from 1992 to 1997 (Randel et al., 1999) revealed two separate features at different altitudes in the stratosphere: 1) a uniform positive trend of $\mathrm{H}_{2} \mathrm{O}+2 \times \mathrm{CH}_{4}$ throughout the stratosphere above $25 \mathrm{~km}$, that is likely due to increasing input of water from the troposphere (Zhou et al., 2001; Rosenlof, 2002; Sherwood, 2002) and 2) superimposed a $\mathrm{H}_{2} \mathrm{O}$ trend which gradually increases with altitude, accompanied by a gradually decreasing trend in methane mixing ratios, which even turns negative at altitudes above about $30 \mathrm{~km}$ (Fig. 6 in Randel et al., 1999). Thus, although $\mathrm{CH}_{4}$ mixing ratios were increasing in the troposphere (Blake and Rowland, 1988; Dlugokencky et al., 2001; Simpson et al., 2001) they were actually decreasing in the middle and upper stratosphere.

This observation indicates that the efficiency of the conversion of $\mathrm{CH}_{4}$ into $\mathrm{H}_{2} \mathrm{O}$ has increased over the considered time period, however, the reasons for this more efficient $\mathrm{CH}_{4}$ oxidation are not fully understood. Nedoluha et al. (1998) carried out model calculations and concluded that the stratospheric $\mathrm{CH}_{4}$ trends could be explained by changes in the vertical transport rate in the tropics. Considine et al. (2001) showed that the disturbance of stratospheric circulation patterns by the eruption of Mount Pinatubo in 1991 might have contributed to, but could not fully account for the observed changes in stratospheric $\mathrm{CH}_{4}$. Rosenlof (2002) recently suggested that changes in the residual circulation can lead to 
increased residence times of $\mathrm{CH}_{4}$ in the stratosphere and thus may contribute to an intensified conversion to $\mathrm{H}_{2} \mathrm{O}$. Here we show that in addition to dynamical mechanisms an increased oxidation of $\mathrm{CH}_{4}$ by $\mathrm{Cl}, \mathrm{O}\left({ }^{1} \mathrm{D}\right)$ and $\mathrm{OH}$ radicals must have caused a more efficient conversion of $\mathrm{CH}_{4}$ to $\mathrm{H}_{2} \mathrm{O}$ in the past decades, and that this mechanism has contributed significantly to the observed $\mathrm{H}_{2} \mathrm{O}$ trends in the middle and upper stratosphere.

\section{Stratospheric in situ production of $\mathrm{H}_{2} \mathrm{O}$}

The relative strengths of the three $\mathrm{CH}_{4}$ sink processes, reaction with $\mathrm{Cl}, \mathrm{O}\left({ }^{1} \mathrm{D}\right)$ and $\mathrm{OH}$, can be obtained from $\mathrm{CH}_{4}$ isotope measurements, because all three reactions are associated with different isotope fractionations. Recent measurements of the heavy isotope content of stratospheric $\mathrm{CH}_{4}$ are reproduced well in atmospheric models when the relative share of the Cl-based stratospheric $\mathrm{CH}_{4}$ sink is 20 to $35 \%$ (Saueressig et al., 2001; McCarthy et al., 2003; Rice et al., 2003). Thus, the reaction with $\mathrm{Cl}$ is an important sink of $\mathrm{CH}_{4}$ in the present day stratosphere. The history of the atmospheric chlorine burden and its increase due to anthropogenic CFC emissions in the second half of the 20th century is well established (Butler et al., 1999; WMO, 2003). An increase of atmospheric CFC levels must inevitably lead to an increased $\mathrm{Cl}$-driven sink of stratospheric $\mathrm{CH}_{4}$. Thus, the conversion of $\mathrm{CH}_{4}$ to $\mathrm{H}_{2} \mathrm{O}$ will become more efficient, which should lead to an increase in stratospheric $\mathrm{H}_{2} \mathrm{O}$ levels at a given altitude.

The most important consequence of anthropogenic CFC emissions was the chlorine catalyzed destruction of ozone in the stratosphere. In addition to the well-known dramatic destruction of stratospheric ozone in polar spring, publicly known as the "ozone hole", ozone has also been reduced by anthropogenic chlorine on a global scale. Observations between 1979 and 1999 show that the decline of $\mathrm{O}_{3}$ is altitude dependent and amounts to $3-6 \%$ per decade in the $40-50 \mathrm{~km}$ altitude range (WMO, 2003). In addition to destruction by $\mathrm{Cl}$, upper stratospheric ozone is also affected by the solar cycle (WMO, 2003). A global ozone decrease in the upper stratosphere causes a further chemical feedback on stratospheric water vapour. The ozone photolysis rate $\mathrm{J}\left(\mathrm{O}_{3}\right)$ and thus the production rate of $\mathrm{O}\left({ }^{1} \mathrm{D}\right)$ critically depends on the ozone column above the photolysis region. The thinning of the ozone column above increases the actinic flux available for the photochemistry of $\mathrm{O}_{3}$ at a certain altitude and thus increases the $\mathrm{O}\left({ }^{1} \mathrm{D}\right)$ production rate. More $\mathrm{O}\left({ }^{1} \mathrm{D}\right)$ production means increased destruction of $\mathrm{CH}_{4}$ and thus enhanced production of $\mathrm{H}_{2} \mathrm{O}$. Moreover, since $\mathrm{OH}$ in the stratosphere is primarily formed via

$\mathrm{O}\left({ }^{1} \mathrm{D}\right)+\mathrm{H}_{2} \mathrm{O} \rightarrow 2 \mathrm{OH}$

a higher $\mathrm{O}\left({ }^{1} \mathrm{D}\right)$ concentration also means more $\mathrm{OH}$ production. Hence, the thinning of the upper stratospheric ozone column must have caused an increase of $\mathrm{O}\left({ }^{1} \mathrm{D}\right)$ and $\mathrm{OH}$ levels and thereby a more efficient conversion of $\mathrm{CH}_{4}$ to $\mathrm{H}_{2} \mathrm{O}$.

According to reaction (1) the increase of water vapour levels in the stratosphere itself will also lead to a higher $\mathrm{OH}$ production rate. Thus both, the additional $\mathrm{H}_{2} \mathrm{O}$ input from the troposphere, as well as the additional $\mathrm{H}_{2} \mathrm{O}$ from more efficient $\mathrm{CH}_{4}$ oxidation as just described, cause higher $\mathrm{OH}$ concentrations and in turn an intensified production of $\mathrm{H}_{2} \mathrm{O}$ from $\mathrm{CH}_{4}$.

In combination, the increase in anthropogenic CFC emissions, the variations in stratospheric ozone and the increased input of tropospheric water into the stratosphere must have caused a more efficient oxidation of $\mathrm{CH}_{4}$ and thus production of $\mathrm{H}_{2} \mathrm{O}$ in the stratosphere. We note that there are additional second order effects, e.g. the $\mathrm{Cl}$ - and $\mathrm{O}\left({ }^{1} \mathrm{D}\right)$-initiated removal of $\mathrm{CH}_{4}$ will produce $\mathrm{OH}$ radicals further along the $\mathrm{CH}_{4}$ oxidation sequence, which will not be discussed here.

\section{Model calculations}

We have carried out stratospheric model calculations to investigate these three effects in detail. Atmospheric models are available at various levels of complexity ranging from box models to high resolution 3-D models. Each of these model types has its particular strengths and weaknesses. For our study we use a chemical box model to focus on the chemical mechanisms that are put forward here. This model neglects atmospheric mixing effects but allows us to correctly describe the age of air in an air parcel rising in the stratosphere in the tropics, a quantity that is often not well reproduced in more complex models (Hall et al., 1999; WMO, 1999). A further advantage of using this box model is that the three effects can be assessed separately by individually including or neglecting the respective changes in the atmospheric composition, constrained by the available observations.

In addition, we have also carried out simulations with a two-dimensional model to investigate the impact of mixing and to examine the latitude dependence of the results. We emphasize again that 2-D (and 3-D) models generally underestimate the mean age of stratospheric air (Hall et al., 1999; WMO, 1999), i.e. they transport air too quickly through the stratosphere. Nevertheless, the results from the box model and from the 2-D model calculations, each having inherent advantages and deficiencies, provide a consistent picture, which gives us confidence that the results presented here are robust and are not dependent on a particular model.

Our box model consists of the chemistry module of the Chemical Lagrangian Model of the Stratosphere (CLaMS) (McKenna et al., 2002). Simulations are performed along an idealized trajectory for a single air parcel that rises from the tropical tropopause $\left(15^{\circ} \mathrm{N}\right)$ to $1 \mathrm{hPa}$ within 4 years, as deduced and extrapolated from observations of water vapour variations ascending in the tropical stratosphere (Mote et al., 
1996; Rosenlof, 2002). As mentioned above, atmospheric mixing is neglected in such box model calculations. This leads to altitude profiles of $\mathrm{CH}_{4}$ mixing ratios that decrease too slowly in the lower stratosphere below about $10 \mathrm{hPa}$ and too quickly above, when compared to stratospheric conditions, where mixing reduces the meridional gradients. Nevertheless, the total removal of $\mathrm{CH}_{4}$ in the model is realistic, and half of the tropospheric $\mathrm{CH}_{4}$ is decomposed at about $3 \mathrm{hPa}$, which is comparable to $\mathrm{HALOE} \mathrm{CH}_{4}$ observations.

Along the path of the considered air parcel the complete stratospheric photochemistry with 98 chemical and 36 photolysis reactions is simulated, including $\mathrm{CH}_{4}$ oxidation and decomposition of CFCs and $\mathrm{N}_{2} \mathrm{O}$. Typical monthly temperature changes are included in the idealized trajectories. Abundances of the radical species $\mathrm{Cl}, \mathrm{OH}$ and $\mathrm{O}\left({ }^{1} \mathrm{D}\right)$ are calculated from their precursors (e.g. $\mathrm{CFCs}, \mathrm{O}_{3}$ or $\mathrm{H}_{2} \mathrm{O}$ itself), using recommended photolysis and chemical rate coefficients (Sander et al., 2000). The air parcel is initialized with a chemical composition taken from simulations with the Mainz photochemical 2-D model (Gidel et al., 1983; Grooß, 1996). The underlying boundary conditions for all box and 2-D model simulations in this study are taken from the WMO scenarios (WMO, 1999; WMO, 2003). Based on these scenarios and the observed trends of water input from the troposphere into the stratosphere (SPARC, 2000; Rosenlof et al., 2001) we then varied for the considered time periods the initial CFC, $\mathrm{H}_{2} \mathrm{O}$ and $\mathrm{CH}_{4}$ content of the air parcel, as well as the ozone profile that was used in the radiative transfer code to determine the photolysis frequencies, to study the effects on stratospheric water vapour mixing ratios. This means that the temporal trends in radical abundances are wherever available based on observed trends of the precursor molecules.

\section{Results}

In Fig. 1a, we show the simulated $\mathrm{H}_{2} \mathrm{O}$ and $\mathrm{CH}_{4}$ trends for the 1980 s, a period with strongly increasing atmospheric $\mathrm{CH}_{4}$ and $\mathrm{CFC}$ emissions. The combined increase of $\mathrm{CH}_{4}$ and CFC levels leads to a substantial stratospheric water increase of up to $0.27 \mathrm{ppm} /$ decade at $1 \mathrm{hPa}$ (black lines), which is more than just the transfer of the tropospheric $\mathrm{CH}_{4}$ trend (green lines). The reduction and even reversal of the $\mathrm{CH}_{4}$ trend at higher altitudes clearly demonstrates that the oxidation of $\mathrm{CH}_{4}$ has become more efficient due to the anthropogenic CFC emissions. This process was previously studied by Nedoluha et al. (1998), who also found increased oxidation of $\mathrm{CH}_{4}$ by $\mathrm{Cl}$ due to increasing $\mathrm{CFC}$ emissions. However, the conclusion from their modelling study over five years was that this effect should be small.

When we also include a decadal increase of water vapour input from the tropopause of $0.5 \mathrm{ppm}$, which equals the average trends from all available measurements (Rosenlof et al., 2001), the corresponding increase in $\mathrm{OH}$ results in further conversion of $\mathrm{CH}_{4}$ to $\mathrm{H}_{2} \mathrm{O}$ (blue lines in Fig. 1). Finally, a

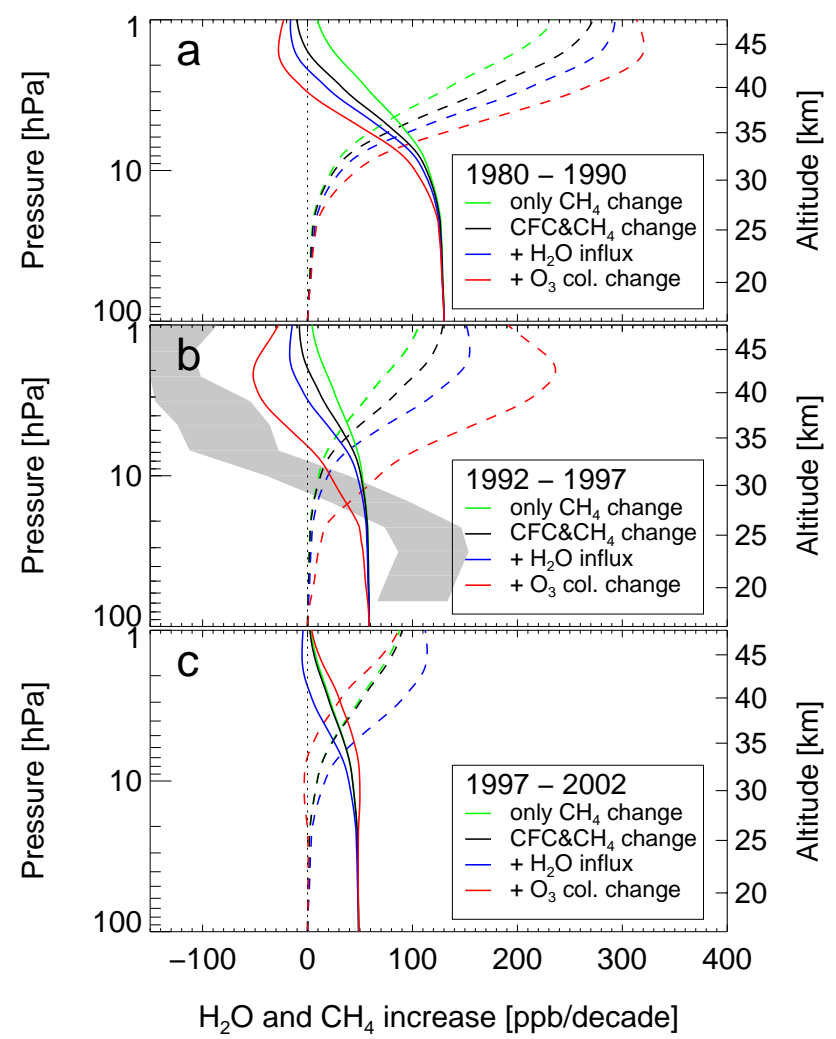

Fig. 1. Box model calculations illustrating the effect of increasing $\mathrm{CH}_{4}$ and CFC levels in the atmosphere, increasing input of water from the troposphere to the stratosphere and a change of the upper stratospheric ozone column on water levels in the stratosphere for the period of the 1980s (a), 1992-1997 (b), and 1997-2002 (c). Solid lines show the $\mathrm{CH}_{4}$ trends and dashed lines the $\mathrm{H}_{2} \mathrm{O}$ trends over the respective periods. The additional $\mathrm{H}_{2} \mathrm{O}$ input from the troposphere of $500 \mathrm{ppb} /$ decade (for the blue and red dashed lines) is subtracted for better reading. In (b), the observational $\mathrm{CH}_{4}$ data from (Randel et al., 1999) are shown as grey-shaded area for comparison.

reduction of the upper stratospheric partial ozone column by $5 \%$ in the $1-10 \mathrm{hPa}$ region (this value is representative for the 1980s, WMO, 2003) also leads to more efficient oxidation of $\mathrm{CH}_{4}$ to $\mathrm{H}_{2} \mathrm{O}$, augmenting the trend due to increased $\mathrm{Cl}$ and $\mathrm{H}_{2} \mathrm{O}$ levels (red lines in Fig. 1). Thus, as argued above, all three chemical effects cause an intensified $\mathrm{CH}_{4}$ oxidation in the stratosphere, leading to a significant increase of upper stratospheric water levels. Since many of the chemical reaction rate coefficients are temperature dependent and stratospheric temperatures have changed over the periods considered here, we carried out sensitivity tests to examine the effect of changing temperatures on the presented model results. For a trend of $2 \mathrm{~K} / \mathrm{decade}$, which is at the upper limit of observational values (WMO, 2003), the effect of the temperature changes was about $10 \mathrm{ppb} /$ decade, i.e. at least one order of magnitude smaller than the combined chemical effects. 

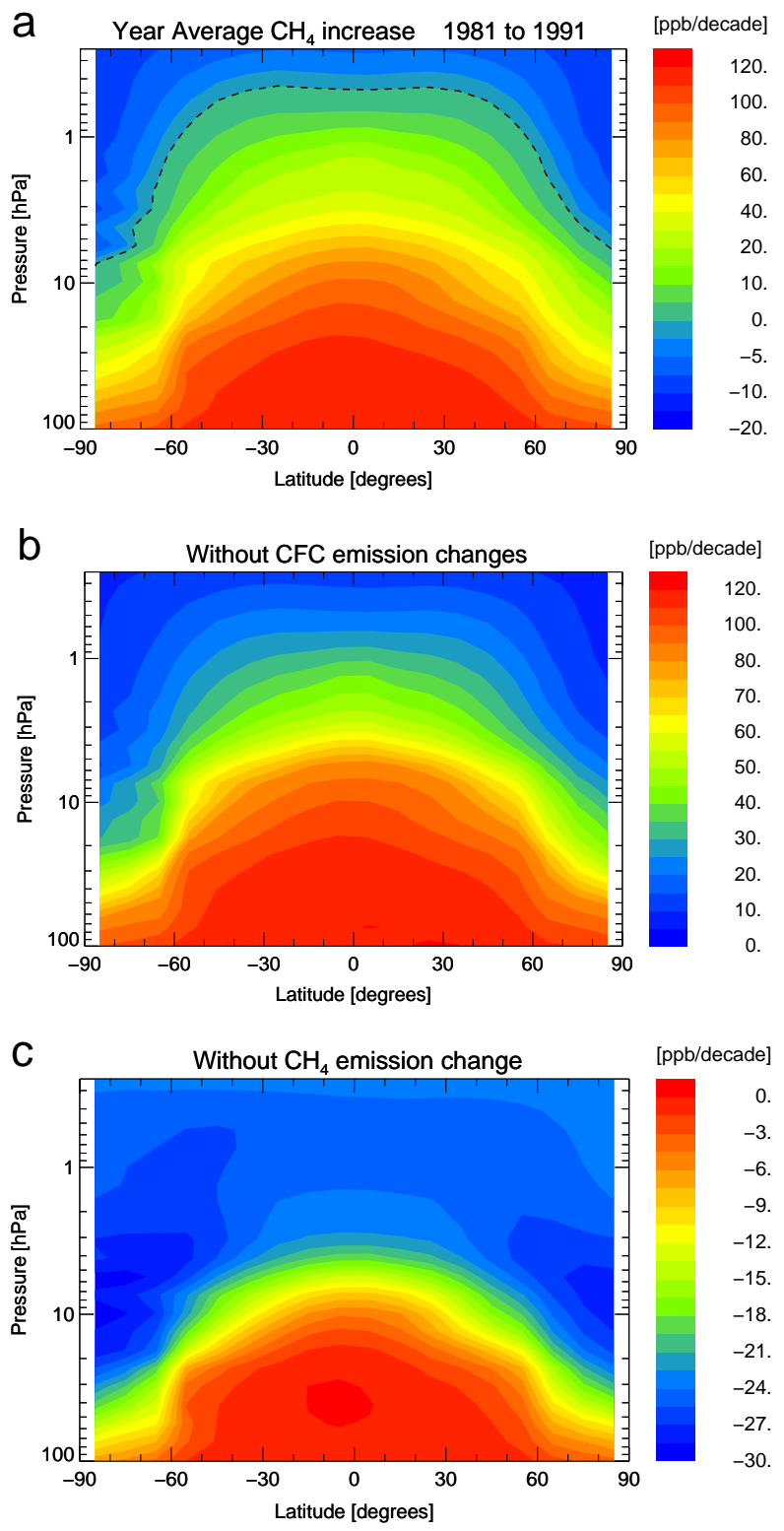

Fig. 2. Results from the Mainz photochemical 2-D model show the latitude dependence of the $\mathrm{CH}_{4}$ trends in the stratosphere for the period 1981-1991 (period shifted by 1 year compared to Fig. 1a to avoid initialization biases). Shown are the differences between model simulations performed under atmospheric conditions representative of 1991 and 1981 based on atmospheric observations: Three scenarios were studied: (a) changing $\mathrm{CH}_{4}$ and $\mathrm{CFC}$ levels from 1981 to 1991 , (b) changing only the $\mathrm{CH}_{4}$ levels and (c) changing only the CFC levels.

The box model results are corroborated by 2-D model calculations. Figure 2 shows the latitudinal distribution of the temporal $\mathrm{CH}_{4}$ trends throughout the stratosphere. In panel (a) we have changed the atmospheric burden of $\mathrm{CH}_{4}$ and CFCs according to the available observations. In panels (b) and (c) the $\mathrm{CFC}$ and $\mathrm{CH}_{4}$ changes, respectively, are switched off. Figure $2 b$ shows that without more efficient oxidation of $\mathrm{CH}_{4}$, i.e. without changes in atmospheric CFC levels, the simulated $\mathrm{CH}_{4}$ trends are positive throughout the stratosphere, a result which is driven by the tropospheric increase of $\mathrm{CH}_{4}$. The temporal trends decrease with increasing residence time in the stratosphere since $\mathrm{CH}_{4}$ is increasingly removed (and thus also the additional input from the troposphere). Figure 2c shows results from simulations where tropospheric $\mathrm{CH}_{4}$ levels were kept constant, and only the CFC increase was considered. The modelled trends are now negative throughout the stratosphere due to more efficient $\mathrm{CH}_{4}$ oxidation by $\mathrm{Cl}$. Figure $2 \mathrm{a}$ shows that when both effects are considered, the general trends are similar to the box model results: $\mathrm{CH}_{4}$ trends switch from positive to negative because the input of $\mathrm{CH}_{4}$ from the troposphere is increasing and because $\mathrm{CH}_{4}$ is more efficiently oxidized to $\mathrm{H}_{2} \mathrm{O}$ throughout the middle and upper stratosphere when its removal rate is enhanced by higher CFC levels. The overall trends are slightly smaller for the 2-D model results than for the box model results, and so in the box model simulations $\mathrm{CH}_{4}$ trends change sign at an altitude slightly higher than deduced from the box model simulations. We note that in the 2-D model only the effects due to the increase of $\mathrm{CH}_{4}$ and $\mathrm{Cl}$ levels (and the corresponding ozone depletion, which is calculated self-consistently) are considered; solar cycle effects on $\mathrm{O}_{3}$ and the increase of $\mathrm{H}_{2} \mathrm{O}$ input from the troposphere are not included. Based on the box model results, including the latter effect would bring the results from the two models into even better agreement. The 2-D simulations also show that the modelled trends depend only moderately on latitude, which confirms that the box model calculations at $15^{\circ} \mathrm{N}$ can be taken as representative for a greater latitude range.

Global satellite observations of stratospheric water vapour from the HALOE instrument became available in late 1991. We now consider the period 1992 to 1997 , for which a strong increase in upper stratospheric $\mathrm{H}_{2} \mathrm{O}$ trends with altitude was reported based on HALOE data (Randel et al., 1999). The period of 1992 to 1997 was a characterized by a decrease in the tropospheric $\mathrm{CH}_{4}$ growth rate (Dlugokencky et al., 1994) and a decline in CFC emissions as a consequence of the Montreal protocol (WMO, 2003). Further, global ozone observations from the HALOE and SAGE II instruments show a strong decline in upper stratospheric ozone. This is likely a solar cycle effect (WMO, 2003) since it happened during the declining phase of the solar cycle, but it has also been associated with the eruption of Mount Pinatubo in 1991 (Randel et al., 1999). For our simulations we use the annual average of $\mathrm{HALOE} \mathrm{O}_{3}$ measurements at $15 \pm 5^{\circ} \mathrm{N}$, the latitude of our box model simulation, from 1992 and 1997, which show a decrease of $3-4 \%$ between 5 and $0.1 \mathrm{hPa}$. The results show that $\mathrm{H}_{2} \mathrm{O}$ production from the increase of $\mathrm{CH}_{4}$ and CFCs alone was much smaller during that period than during the 1980s (Fig. 1b). However, the large change in the $\mathrm{O}_{3}$ column more than compensates for the reduced chlorine and $\mathrm{CH}_{4}$ increase, and the additional oxidation of $\mathrm{CH}_{4}$ is even stronger than in the 1980s. 
Thus, the altitude dependence of the trends from 1992 to 1997 which were observed in the stratosphere (Randel et al., 1999) is reproduced in the model results shown in Fig. 1b: $\mathrm{CH}_{4}$ trends decline and even turn negative at high altitudes and $\mathrm{H}_{2} \mathrm{O}$ trends slowly increase with altitude. The chemical changes discussed here can account for about $50 \%$ of the observed atmospheric $\mathrm{CH}_{4}$ trends (Fig. 1b). The most important contributor to the trends from 1992 to 1997 is the decline in upper stratospheric ozone. This also implies that the HALOE derived $\mathrm{H}_{2} \mathrm{O}$ trend during the early 1990s was biased by solar cycle related variations in atmospheric ozone changes in a manner not recognized previously. This finding is supported by investigations of longer HALOE time series, which generally show smaller temporal trends (Rosenlof, 2002).

Over the years 1997-2002, the increase in upper stratospheric $\mathrm{H}_{2} \mathrm{O}$ as observed by HALOE was negligible (Rosenlof, 2002; Nedoluha et al., 2003). We also investigated the chemical changes for this period. Since the period 1997-2002 was within an increasing phase of the 11 year solar cycle, upper stratospheric $\mathrm{O}_{3}$ increased and we use an increase of $1-3 \%$ between 5 and $0.1 \mathrm{hPa}$, derived from the HALOE data. Owing to the regulations under the Montreal protocol, the stratospheric chlorine loading was almost unchanged (WMO, 2003). Figure 1c shows that there is indeed no effect due to CFC emissions, but the global increase of tropospheric $\mathrm{CH}_{4}$ mixing ratios still caused $\mathrm{H}_{2} \mathrm{O}$ mixing ratios to increase in the upper stratosphere. This is augmented by increased water input from the troposphere, while the increase of the $\mathrm{O}_{3}$ column now actually diminishes the increase of $\mathrm{H}_{2} \mathrm{O}$. In combination, all effects together produce only a small increase of up to $80 \mathrm{ppb} /$ decade, thus $40 \mathrm{ppb}$ over the 5 year period. This is less than in the earlier periods, in agreement with the observations, which do not show a significant trend for $\mathrm{H}_{2} \mathrm{O}$ in the period 1997-2002.

\section{Future development of stratospheric $\mathrm{H}_{2} \mathrm{O}$ trends}

The model results presented above show that anthropogenic CFC emissions, the resulting thinning of the upper stratospheric ozone column as well as the chemical effect of increased water input from the troposphere have led to a significant increase in middle and upper stratospheric water at a given altitude since the 1980s. Further, solar cycle effects have a strong impact, and have partly masked the long-term trends in the 1990s, the first decade of global satellite observations. It is predicted that with the regulations of CFCs under the Montreal protocol, chlorine levels in the stratosphere will decrease further in the future, and that the ozone depletion will slow down and will eventually reverse (WMO, 1999, 2003). Figure 3 shows box model predictions for upper stratospheric water trends from 2000 to 2050 . In these calculations we have assumed future stratospheric chlorine levels based on the WMO halocarbon baseline scenario (Table 4B-3

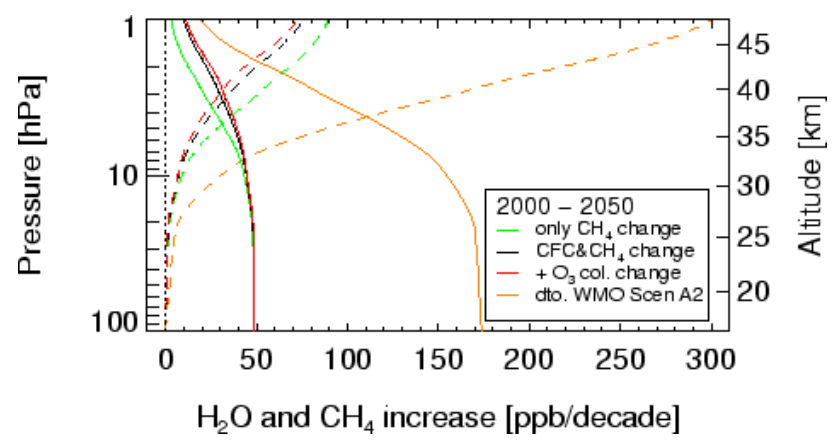

Fig. 3. Future scenario for the increase in stratospheric water vapor taking into account projections for $\mathrm{CH}_{4}$ increase, the decrease in stratospheric chlorine and the recovery of stratospheric ozone. Solid lines show the $\mathrm{CH}_{4}$ trends and dashed lines the $\mathrm{H}_{2} \mathrm{O}$ trends. The green, black and red lines depict the individual effects (colours correspond to Fig. 1) calculated for a projected $\mathrm{CH}_{4}$ increase according to the WMO baseline scenario (Table 12.2 in WMO, 1999). The orange line is the final result (i.e. corresponding to the red line) for a $\mathrm{CH}_{4}$ increase according to WMO scenario A2 (Table 4B-3 in WMO, 2003).

in WMO, 2003). Also tropospheric $\mathrm{CH}_{4}$ mixing ratios follow the WMO baseline scenario (Table 12.2 in WMO, 1999), i.e. they increase to $2000 \mathrm{ppb}$ in the year 2050 . The ozone profiles used come from a 2-D model simulation driven by these scenarios. The results show that primarily the assumed continuing increase of atmospheric $\mathrm{CH}_{4}$ will cause upper stratospheric water levels to increase further (Fig. 3). In contrast to the conditions in the $1980 \mathrm{~s}$, the decline in chlorine and the recovery of stratospheric ozone will reduce the increase of $\mathrm{H}_{2} \mathrm{O}$, i.e. they cause a less efficient conversion of $\mathrm{CH}_{4}$ to $\mathrm{H}_{2} \mathrm{O}$ in the future. Since the future $\mathrm{CH}_{4}$ increase is difficult to predict (Simpson et al., 2002), this important contribution to the $\mathrm{H}_{2} \mathrm{O}$ trends is uncertain: The orange lines in Fig. 3 show the results employing alternatively the WMO scenario A2 (Table 4B-3 in WMO, 2003) with an increase of tropospheric $\mathrm{CH}_{4}$ to $2562 \mathrm{ppb}$ in 2050. Also, the future development of the input of tropospheric water into the stratosphere is very speculative and is therefore not included in the prediction, and neither is the possible impact of a future hydrogen economy as a potential additional source of stratospheric water, as discussed recently (Tromp et al., 2003).

\section{Conclusions}

Increases in the stratospheric abundance of stratospheric abundances of $\mathrm{Cl}, \mathrm{O}\left({ }^{1} \mathrm{D}\right)$ and $\mathrm{OH}$ due to anthropogenic $\mathrm{CFC}$ emissions, the thinning of the stratospheric ozone column and increasing input of water from the troposphere to the stratosphere have led to enhanced chemical conversion of $\mathrm{CH}_{4}$ to $\mathrm{H}_{2} \mathrm{O}$ in the past decades. Clearly, the more efficient oxidation of $\mathrm{CH}_{4}$ as described here cannot explain the observed increase in the quantity $\mathrm{H}_{2} \mathrm{O}+2 \times \mathrm{CH}_{4}$ in the 
stratosphere. Likewise, this chemical mechanism is unlikely to cause large interannual and spatial variability in the trends, and we expect that this variability may be caused by dynamical changes (Considine et al., 2001; Rosenlof, 2002). Nevertheless, the comparison of model simulations and observations indicates that approximately $50 \%$ of the observed enhanced oxidation of $\mathrm{CH}_{4}$ in the stratosphere can be attributed to chemical changes. Thus, these chemical changes, which are based on reliable atmospheric observations and well-established chemical reaction mechanisms, have to be taken into account when stratospheric water vapour trends are analysed. We conclude that this chemical mechanism constitutes an important contribution to the explanation of the total stratospheric water trends.

Acknowledgements. We would like to thank W. J. Randel for providing the observational data shown in Fig. 1b, and T. Peter and M. G. Lawrence for useful discussion on the subject.

Edited by: M. Dameris

\section{References}

Blake, D. R. and Rowland, F. S.: Continuing Worldwide Increase in Tropospheric Methane, 1978 to 1987, Science, 239, 1129-1131, 1988.

Butler, J. H., Battle, M., Bender, M. L., Montzka, S. A., Clarke, A. D., Saltzman, E. S., Sucher, C. M., Severinghaus, J. P., and Elkins, J. W.: A record of atmospheric halocarbons during the twentieth century from polar firn air, Nature, 399, 749-755, 1999.

Considine, D. B., Rosenfield, J. E., and Fleming, E. L.: An interactive model study of the influence of the Mount Pinatubo aerosol on stratospheric methane and water trends, J. Geophys. Res., 106, 27 711-27 727, 2001.

Dlugokencky, E. J., Masarie, K. A., Lang, P. M., Steele, P. P., and Nisbet, E. G.: A dramatic decrease in the growth rate of atmospheric methane in the northern hemisphere during 1992, Geophys. Res. Lett., 21, 45-48, 1994.

Dlugokencky, E. J., Walter, B. P., Masarie, K. A., Lang, P. M., and Kasischke, E. S.: Measurements of an anomalous global methane increase during 1998, Geophys. Res. Lett., 28, 499-502, 2001.

Dvortsov, V. L. and Solomon, S.: Response of the stratospheric temperatures and ozone to past and future increases in stratospheric humidity, J. Geophys. Res., 106, 7505-7514, 2001.

Forster, P. M. D. and Shine, K. P.: Assessing the climate impact of trends in stratospheric water vapor, Geophys. Res. Lett., 29, doi:10.1029/2001GL013909, 2002.

Gidel, L. T., Crutzen, P. J., and Fishman, J.: A Two-Dimensional Photochemical Model of the Atmosphere, 1. Chlorocarbon Emissions and Their Effect on Stratospheric Ozone, J. Geophys. Res., 88, 6622-6640, 1983.

Grooß, J.-U.: Modelling of Stratospheric Chemistry based on HALOE/UARS Satellite Data, Ph. D. thesis, University of Mainz, 1996.

Hall, T. M., Waugh, D. W., Boering, K. A., and Plumb, R. A.: Evaluation of transport in stratospheric models, J. Geophys. Res., 104, 18 815-18 839, 1999.
Jones, R. L., Pyle, J. A., Harries, J. E., Zavody, A. M., Russell, J. M., and Gille, J. C.: The Water-Vapor Budget of the Stratosphere Studied Using LIMS and SAMS Satellite Data, Quart. J. Roy. Met. Soc., 112, 1127-1143, 1986.

Kirk-Davidoff, D. B., Hintsa, E. J., Anderson, J. G., and Keith, D. W.: The effect of climate change on ozone depletion through changes in stratospheric water vapour, Nature, 402, 399-401, 1999.

McCarthy, M. C., Boering, K. A., Rice, A. L., Tyler, S. C., Connell, P., and Atlas, E.: Carbon and hydrogen isotopic compositions of stratospheric methane: 2. Two-dimensional model results and implications for kinetic isotope effects, J. Geophys. Res., 108, doi:10.1029/2002JD003183, 2003.

McKenna, D. S., Grooß, J.-U., Gunther, G., Konopka, P., Müller, R., Carver, G., and Sasano, Y.: A new Chemical Lagrangian Model of the Stratosphere (CLaMS): 2. Formulation of chemistry scheme and initialization, J. Geophys. Res., 107, doi:10.1029/2000JD000114, 2002.

Mote, P. W., Rosenlof, K. H., McIntyre, M. E., Carr, E. S., Gille, J. C., Holton, J. R., Kinnersley, J. S., Pumphrey, H. C., Russel, J. M., and Waters, J. W.: An atmospheric tape recorder: The imprint of tropical tropopause temperatures on stratospheric water vapor, J. Geophys. Res., 101, 3989-4006, 1996.

Nedoluha, G. E., Siskind, D. E., Bacmeister, J. T., Bevilacqua, R. M., and Russell, J. M.: Changes in upper stratospheric $\mathrm{CH}_{4}$ and $\mathrm{NO}_{2}$ as measured by HALOE and implications for changes in transport, Geophys. Res. Lett., 25, 987-990, 1998.

Nedoluha, G. E., Bevilacqua, R. M., Gomez, R. M., Hicks, B. C., Russell, J. M., and Connor, B. J.: An evaluation of middle atmospheric water vapor as measured by HALOE, WVMS, and POAM, J. Geophys. Res., 108, doi:10.1029/2002JD003332, 2003.

Oltmans, S. J. and Hofmann, D. J.: Increase in lower-stratospheric water vapour at a mid-latitude Northern Hemisphere site from 1981 to 1994, Nature, 374, 146-149, 1995.

Oltmans, S. J., Vömel, H., Hofmann, D. J., Rosenlof, K. H., and Kley, D.: The increase in stratospheric water vapor from balloonborne, frostpoint hygrometer measurements at Washington, D.C., and Boulder, Colorado, Geophys. Res. Lett., 27, 34533456, 2000.

Randel, W. J., Wu, F., Russell, J. M., and Waters, J.: Space-time patterns of trends in stratospheric constituents derived from UARS measurements, J. Geophys. Res., 104, 3711-3727, 1999.

Rice, A. L., Tyler, S. C., McCarthy, M. C., Boering, K. A., and Atlas, E.: Carbon and hydrogen isotopic compositions of stratospheric methane: 1. High-precision observations from the NASA ER-2 aircraft, J. Geophys. Res., 108, doi:10.1029/2002JD003042, 2003.

Rosenlof, K. H.: Transport changes inferred from HALOE water and methane measurements, J. Meteorol. Soc. Japan, 80, 831848, 2002.

Rosenlof, K. H., Oltmans, S. J., Kley, D., Russell, J. M., Chiou, E. W., Chu, W. P., Johnson, D. G., Kelly, K. K., Michelsen, H. A., Nedoluha, G. E., Remsberg, E. E., Toon, G. C., and McCormick, M. P.: Stratospheric water vapor increases over the past halfcentury, Geophys. Res. Lett., 28, 1195-1198, 2001.

Sander, S. P., Friedl, R. R., DeMore, W. B., Golden, D. M., Kurylo, M. J., Hampson, R. F., Huie, R. E., Moortgat, G. K., Ravishankara, A. R., Kolb, C. E., and Molina, M. J.: Chemical ki- 
netics and photochemical data for use in stratospheric modeling, Supplement to evaluation 12: Update of key reactions, JPL Publication 00-3, 2000.

Saueressig, G., Crowley, J. N., Bergamaschi, P., Brühl, C., Brenninkmeijer, C. A. M., and Fischer, H.: Carbon 13 and D kinetic isotope effects in the reactions of $\mathrm{CH}_{4}$ with $\mathrm{O}\left({ }^{1} \mathrm{D}\right)$ and $\mathrm{OH}$ : New laboratory measurements and their implications for the isotopic composition of stratospheric methane, J. Geophys. Res., 106, 23 127-23 138, 2001.

Sherwood, S.: A microphysical connection among biomass burning, cumulus clouds, and stratospheric moisture, Science, 295, 1272-1275, 2002.

Simpson, I. J., Blake, D. R., Rowland, F. S., and Chen, T. Y.: Implications of the recent fluctuations in the growth rate of tropospheric methane, Geophys. Res. Lett., 29, doi:10.1029/2001GL014521, 2002.
SPARC (Stratospheric Processes and Their Role in Climate): Assessment of Upper Tropospheric and Stratospheric Water Vapour, SPARC Report No. 2, WCRP 113, 312, World Meteorological Organization, Geneva, 2000.

Tromp, T. K., Shia, R.-L., Allen, M., Eiler, J. M., and Yung, Y. L.: Potential Environmental Impact of a Hydrogen Economy on the Stratosphere, Science, 300, 1740-1742, 2003.

WMO (World Meteorological Organization): Scientific Assessment of Ozone Depletion: 1998, Global Ozone Research and Monitoring Project, Report Nr. 44, 498, Geneva, 1999.

WMO (World Meteorological Organization): Scientific Assessment of Ozone Depletion: 2002, Global Ozone Research and Monitoring Project, Report Nr. 47, 498, Geneva, 2003.

Zhou, X. L., Geller, M. A., and Zhang, M. H.: Cooling trend of the tropical cold point tropopause temperatures and its implications, J. Geophys. Res., 106, 1511-1522, 2001. 